\title{
UNA AUSENCIA EN EL CANON: \\ LOS DISCURSOS COLONIALES SOBRE EL URUGUAY \\ EN EL MARCO DE LA HISTORIOGRAFÍA LITERARIA URUGUAYA Y LOS ESTUDIOS COLONIALES LATINOAMERICANOS
}

\author{
POR \\ Gustavo Verdesio \\ University of Wisconsin-Parkside
}

$\mathrm{Ni}$ las historias de la literatura uruguaya ni los estudios coloniales latinoamericanos hacen mención a los textos coloniales sobre el Uruguay. ${ }^{1}$ Las siguientes líneas son un intento de incorporar esos textos (que existen, a pesar de que se los ha ignorado) a ambas áreas de estudio. Por ello me voy a ocupar de algunos de los problemas que esa operación pueda plantear a ambos campos de investigación. Primero me centraré en los criterios que informan la práctica disciplinaria en el Uruguay (en ese contexto es donde habrá más dificultades para la incorporación, debido a los criterios que rigen para la formación del canon). Luego me ocuparé, brevemente, de su incorporación al corpus colonial latinoamericano (que no presentará mayores problemas, debido a la dirección que hoy están tomando esos estudios). Luego de sugerir un nuevo sistema de "canonicidad" señalaré las peculiaridades de los textos coloniales sobre el Uruguay y algunas estrategias para su estudio.

Basta pasar revista a las historias de la literatura uruguaya más comprensivas para percibir coincidencias, a pesar de las diferencias de criterio que exhiben entre sí, en puntos que pueden ser considerados esenciales. La primera que se puede señalar radica en el establecimiento del comienzo, del punto de partida de la literatura nacional. Montero Bustamante sostiene lo siguiente: "La poesía nacional del Uruguay fue un producto genuino

\footnotetext{
' Cuando me refiero al Uruguay lo hago desde una perspectiva diacrónica. Es decir, como descripción definida (en el sentido que le dan los lógicos) del largo proceso de producción de ese referente ("Uruguay"). Ese referente será, en tiempos coloniales, el territorio de lo que es hoy el Uruguay. Más adelante (en este mismo artículo) discutiré el criterio referencial propuesto por Mignolo. Para una descripción (y fundamentación) de esta estrategia puede verse mi tesis doctoral "Hacia una historia, donde abogo por la necesidad de estudiar los textos coloniales sobre esa región de América, a fin de restituir a ese referente ("América") las partes que le están faltando (el corpus colonial no incluye los textos que construyen el territorio del Plata como referente). Para un tratamiento de algunos de los problemas teóricos que esto plantea puede verse mi trabajo "Escritura e identidad". Un detalle interesante es que ya en 1602 Hernandarias (gobernador del Paraguay) llamaba a ese territorio "tierras de Vruay".
} 
de la Revolución americana" (subrayado mío). ${ }^{2}$ Esta misma opinión fue sustentada unos años después por Carlos Roxlo, en su historia de la literatura uruguaya; allí establece como su primer período el que va de los años 1810 a $1840 .^{3}$ Medio siglo más tarde, Sarah Bollo afirma que "Nuestra literatura nace con el movimiento de la independencia, al liberarnos del dominio hispánico en 1810" (13). Claro que siempre existen antecedentes para ese momento inicial, y así lo hace notar la autora, incluso desde el título, y en el primer párrafo de su obra: "Hay, sin embargo, algunas producciones anteriores, de los años 1807 y 1808" (13). Por ello, se aboca a analizar en detalle algunas producciones previas al año inaugural. ${ }^{4}$ El mismo criterio puede verse en la compilación de poesía uruguaya de Julio J. Casal (11). Zum Felde también, en su Proceso intelectual del Uruguay, reconoce la existencia de esos autores "primitivos" al presentarlos en el numeral III de su capítulo inicial (49-66). Gustavo Gallinal, a su vez, acusa recibo de los mismos al comentar algunos de ellos, los que se produjeron en fecha anterior a $1810 \mathrm{y}$ aparecen en el Parnaso Oriental de Luciano Lira (5-31). Bauzá incluso considera a uno de estos textos primitivos (la obra del padre Martínez) como el que marca el comienzo de la literatura uruguaya.

Como puede apreciarse, las opiniones de los estudiosos de la literatura uruguaya son similares en lo referente a este tema. Pero hay otros, no menos importantes, en que los hallamos estrechando filas y formando juntos. Por ejemplo, en el alcance que debe darse a la noción de literatura. En este sentido, la toma de partido es por un concepto de literatura que la identifique con las bellas letras. ${ }^{6}$ Una noción de origen europeo, hecha universal por obra y gracia de las prácticas imperialistas de esa cultura. ${ }^{7}$ La axiología que la informa

${ }^{2}$ Y continúa: "El cambio de régimen trajo una alteración absoluta en la vida de las antiguas colonias españolas. Dentro de las ciudades del Virreynato no había florecido el arte como expresión sincera del alma de aquellos pueblos; una imitación incolora de los autores en voga regía la escasa producción literaria" (5).

${ }^{3} \mathrm{Su}$ argumento es el que sigue: "Nuestra literatura, como todas las literaturas sudamericanas, nace con el movimiento que nos independiza del dominio español. Sólo algún tiempo antes de alejarse de nuestras playas la bandera en que se hiergue el león castellano, nuestra prosa y nuestra poesía luchan por adquirir un carácter propio, no en la forma que es imitativa y clásica, sino en los asuntos, que unas veces se refieren a cosas del país, y que otras veces tratan del movimiento autonómico que enardecía á los espíritus de aquella edad de hierro" (subrayados míos, 26).

${ }^{4}$ Que son básicamente las mismas que Bollo menciona como antecedentes. Más adelante veremos a qué obras nos estamos refiriendo.

5 "Fué pues el teatro nacional, punto de partida del movimiento literario uruguayo: y por él empezaron nuestros poetas la batalla contra el ideal español, buscando a sacudir por las letras, el yugo de la tradición que más tarde habían de romper las multitudes con las armas. La oportunidad del primer ensayo la aprovechó el P. Don Juan F. Martínez, con ocasión de un festejo eminentemente local, y que llenaba de orgullo a los orientales. Tratábase de conmemorar la reconquista de Buenos Aires por las fuerzas expedicionarias que habían partido de Montevideo en 1806" (Bauzá 72-73).

${ }^{6}$ En un campo más amplio (el hispanoamericano), la noción de literatura que predomina es del mismo tipo (Achugar, "Literatura/literaturas" 158-159).

7 "mientras que la discursividad oral ... se identifica con la historia del homo sapiens, la literatura es 'regional' y se identifica, primero, con la invención de la escritura y, segundo, con una conceptualización particular de determinados discursos en escritura alfabética en la Europa del siglo XVIII. El hecho de que la escritura sea tardía en la historia de la humanidad y la 'invención de la 
se basa en la exclusión (del ámbito de lo literario) de aquellos textos que no respondan a determinada preceptiva. Es decir que valores tales como belleza y perfección formal serán los que distingan a un texto literario de uno que no lo es. ${ }^{8}$

En realidad, no era necesaria una declaración explícita de parte de los críticos, ya que los valores que sustentan se desprenden de los conjuntos de textos que han elegido para representar la producción literaria uruguaya. En efecto, en el corpus propuesto por cada uno de los críticos nombrados, casi no encontramos textos que excedan los límites de los presupuestos enunciados por Roxlo. Cuando obras de índole no belleletrística aparecen mezcladas con las otras, su ocurrencia es sólo ocasional y a modo de excepción. No ocurre exactamente así con la citada antología de Casal, donde el compilador parece justificar con argumentos extraliterarios la inclusión de poemas "malos" desde un punto de vista estético." Pero un poema, por más que sea "malo" si lo evaluamos con un criterio belleletrístico, no deja por ello de ser un poema. Es más, no cesa de ser un poema inspirado (aunque sus logros "estéticos" no sean los deseados por su autor) y juzgado desde esos patrones que lo condenan. Por ejemplo, cuando Gustavo Gallinal comenta los textos de Prego de Oliver, dice que sus poemas: "son todavía de los más fluidos y correctos y, a falta de reales bellezas, tienen estas cualidades negativas, denunciando en su autor a un escritor de cierta ilustración para el medio y el momento y de alguna facilidad y destreza en el manejo del verso" (21). ${ }^{10}$ Como se puede apreciar, la evaluación de esos textos surge de

letra' (escritura alfabética) aún más tardía que la invención de la escritura, incrementa la paradoja según la cual el restringido ámbito de la letra y de la literatura se imponga como un universal de la cultura" (Mignolo, "Teorizar" 107).

${ }^{8}$ Este criterio es claramente expuesto (aunque después de juguetear por un momento con una noción más amplia - y comprensiva - de literatura) por Carlos Roxlo: "En buena lógica, si atendiésemos sólo a su etimología, podríamos decir que todas las obras escritas por el hombre son obras literarias, aunque esas obras traten de teodicea, legislación, medicina, ó náutica. Sin embargo, restrictivamente y por convenio unánime, se entiende por literatura el conjunto de obras escritas que tienen á la belleza por objeto principalísimo, siendo la literatura un arte cuando trata de los principios técnicos á que obedecen las obras literarias, y siendo la literatura una ciencia cuando trata de la filosofia de la producción intelectual de la belleza. En toda obra literaria, $\sigma$ sea en toda obra cuyo fin primordial es la hermosura, es forzoso atender á la forma y al fondo, porque siendo la belleza el fin supremo de esta índole de producciones, el fondo y la forma deben asociarse para embriagarnos con los zumos del placer calológico, con el vino tonificante del deleite estético" (15).

9 "Si se entiende por antología, una selección de valores, ésta no lo sería, ni tendría motivos para serlo. Nosotros hemos querido dar una "Exposición de la Poesía Uruguaya", haciendo que pase en estas páginas ante los ojos del lector, todo lo que el país ha tenido de alguna significación. Hay en este libro, poesía, con gran seguridad poca, y versos, con no menos seguridad, muchos" (sin página). ${ }^{10}$ Bauzá también pasa revista, benévolamente, a algunos de los autores "primitivos" del Uruguay (el Padre Martínez y algunos de los que aparecen en el Parnaso Oriental). Desde su perspectiva, el valor de los textos analizados es más testimonial que artístico, basándose para emitir tal juicio de valor en los patrones literarios tributarios de la noción de bellas letras: "hemos de inquirir los rasgos fisonómicos de nuestra sociedad de 1811 , en el arsenal popular de sus crónicas versificadas, sin cuidarnos de los cronistas y aún de su corrección, en cuanto importe al espíritu que informa esos relatos accidentales; bien entendido empero que esto no implica proclamar la indulgencia plenaria a sus pecados literarios, sino dejar establecido cuando más, que no por causa de los pecados debe hacerse caso omiso de los pecadores" (64). 
su comparación con ciertos patrones y medidas de origen "literario". El mismo criterio anima a Zum Felde, quien siempre busca la "literariedad" de los textos que analiza (Proceso intelectual 49-66). ${ }^{11}$

He dejado para el final el comentario de una de las historias más recientes de la literatura uruguaya, Capitulo Oriental. Por una buena razón: en la sección dedicada a los tiempos coloniales, a cargo de Carlos Maggi, se ofrece un criterio de selección diferente al de los críticos comentados hasta ahora. Si bien no es la primera vez en la historiografía literaria uruguaya que se incluyen textos no definibles como literarios stricto sensu (como poemas, obras de teatro, etcétera ${ }^{12}$ ), sí es la primera en que se ofrece el siguiente criterio para la justificación de su inclusión:

el sentido tradicional que se da a la expresión literatura, ha despistado casi sin excepción a los estudiosos del tema y en consecuencia, prácticamente, todo lo escrito sobre el primer período de nuestras letras se refiere a "obras literarias" que son convencionales y endebles - casi siempre olvidables en sí mismas-, y deja de lado valiosas páginas que se escribieran a fines del siglo XVIII y principios del XIX que no presentan las características exteriores de la poesía, la narración, el teatro, o los demás géneros descritos en los manuales. Pero la función del crítico consiste en descubrir los valores allí donde estén, se encuentren donde se encuentren, ordenarlos y ponerlos de manifiesto; y en nuestro caso sucede que, por lo regular, hay más y mejor literatura, literatura más aprovechable, en los escritos políticos, históricos y científicos de la época, que en las páginas de querida y no lograda creación lírica y narrativa. Corresponde, pues, revisar los criterios tradicionales. (subrayados míos, 50)

Como se puede apreciar, este crítico se desvía de los caminos ya señalados, pero tan sólo parcialmente, ya que su criterio de selección es todavía tributario de la dictadura de las "Bellas Letras": el mismo consiste principalmente en descubrir e invocar los rasgos ("los valores") "literarios" de los que aquellos textos no-literarios serían portadores. Al comparar la cantidad de "literatura" que se halla en textos "no literarios" y "literarios malos" de la época, se percata de que son los primeros los que salen mejor parados; por ello los preferirá a los que por su intención y su forma son, en apariencia, más "literarios". Es la belleza y la perfección formal, la "literatura" que contienen (aunque en forma esporádica y quizá no buscada) lo que amerita que un grupo de obras sea incluido en el corpus de la literatura uruguaya. Por si cupiera alguna duda sobre la noción de literatura a la que este crítico se adhiere, vaya como muestra este párrafo: "sería vano intentar la historia de algo que en el sentido usual de la palabra no existía: literatura propiamente dicha" (49).

" Un buen ejemplo de ello es el pasaje en que comenta la obra del padre Martínez: "Muy lejos está por cierto, la modesta alegoría escénica del canónigo montevídeano, de alcanzar los valores del verdadero teatro, asi por la ingenuidad, algo bárbara, de sus formas, como por la general trivialidad retórica de sus versos. Sin embargo, considerada dentro de su ambiente y de su hora - es decir, con criterio más histórico, que estético - no está la pieza totalmente desprovista de méritos" (subrayados míos) (59). Se percibe aquí un criterio similar al de Bauzá, referido en la nota anterior.

${ }^{12}$ Ya Zum Felde incluía textos de Pérez Castellano y Larrañaga que no podían considerarse "literarios", pero que poséan considerable valor histórico, como el mismo historiador se encarga de declarar (Proceso intelectual 51-56). 
Pero sería injusto si no se destacara que, a pesar de su adhesión a cierta noción de literatura, Maggi va más lejos que sus colegas en su audacia renovadora del corpus literario uruguayo:

se han seleccionado autores nacidos en nuestro territorio - caso de Pérez Castellano y de Larrañaga, ambos de Montevideo-, pero también aparecen varios españoles y, en un caso, un viajero escocés que escribe en lengua inglesa .... Ni en materia de géneros, ni en materia de nacionalidades y aún de lenguas, se puede ser muy riguroso cuando todo está empezando a hacerse, en medio de la mayor miseria y confusión. (50-51)

Es interesante comprobar que en la historiografia literaria de un país vecino al Uruguay, la explicitación de este criterio ya existía desde hace tiempo. Ricardo Rojas declara, con respecto a la nacionalidad de los autores que: "La cuna es un accidente biológico, y por sí sola nada vale, si no se le corrobora por el factor psicológico de la conciencia, por el factor social de la educación, por el factor histórico de una vida en favor de la tierra donde nacimos y de la comunidad política a la cual pertenecemos" (Los gauchescos 36).

Ya veremos, más adelante, cómo este crítico argentino da también una serie de pasos decisivos para la ampliación del corpus literario nacional argentino. Pero volviendo a la propuesta de Maggi, se puede apreciar que va mucho más lejos que la de sus predecesores en lo que se refiere a ensanchar el corpus de textos que conforman una literatura. Sin embargo, es evidente que todavía responde de manera bastante directa a criterios rectores de corte similar a los expuestos por Roxlo. ${ }^{13}$

En el presente trabajo no intento seguir los mandatos y preceptos tradicionalmente aceptados en las letras uruguayas. El criterio de selección que manejo es muy diferente; uno que no tiene relación alguna con la perfección formal ni con la belleza que los objetos de estudio exhiban (de ahí surgen los problemas para incorporar los textos que propongo al corpus de la literatura uruguaya). Antes de definir el criterio que propongo, es pertinente aclarar, por cuestiones metodológicas y prácticas, qué significará, de aquí en adelante, la palabra literatura (entre otras razones, para no tener que entrecomillarla).

Cuando hable de literatura estaré queriendo aludir a una de las entidades que Foucault llama formaciones discursivas; es decir, aquellos conjuntos de enunciados pasibles de constituir sistemas que conocemos con el nombre de, por ejemplo, literatura, filosofía, medicina, etcétera (50-64). Según este autor, estas formaciones toman la forma de un campo en el que se percibe (y tiene lugar) un sistema de dispersión (o tablas de diferencias) entre los enunciados que lo constituyen (62). Es decir que sólo en este sentido institucional, forjado a través de una praxis y de una tradición (y no porque crea que la organización de los enunciados de la formación discursiva literatura difiera en esencia de la de otras formaciones discursivas), voy a utilizar la palabra literatura. De modo que si nos encontramos con un soneto o una tragedia, no dejaré de llamar a estas obras literatura; la

\footnotetext{
${ }^{13}$ Si bien creo que Maggi tuvo autonomía al redactar su fascículo de Capitulo Oriental, habría que precisar aquí que la colección estaba bajo la supervisión de Carlos Real de Azúa, cuyas concepciones acerca de lo que es literatura (o lo que es cultura), eran de carácter más abierto, como lo atestiguan los fascículos de la misma colección dedicados a los cronistas, humoristas, artes plásticas, fútbol, etcétera.
} 
razón para así nombrarlas está fundada más en cuestiones históricas y prácticas que en las propiedades intrínsecas de dicha formación discursiva qua semiosis.

Decía más arriba que los criterios de selección que se proponen en este trabajo son de índole notoriamente diferente a los de los historiógrafos literarios uruguayos. En primer lugar, como ya adelantara, porque no adhiero a la preceptiva belleletrística, por considerarla limitadora de las posibilidades del crítico cuando se encuentra frente a la tarea de dar cuenta de un universo discursivo determinado. Además del empobrecimiento del objeto de estudio, esta perspectiva genera una distorsión del mismo, al excluir concientemente actos verbales que, como veremos luego, tienen gran relevancia para la comprensión del antedicho universo. Walter Mignolo afirma que esos "actos verbales conservados en la memoria colectiva y de alta significación en la organización de una cultura" deben ser considerados textos y que dicha cultura conserva esos textos como textos de una cierta clase ("Cartas, crónicas" 57), al tiempo que esta pertenencia a clases admite, a su vez, diversos niveles de inclusión. ${ }^{14}$

Este crítico, que está trabajando sobre el período colonial de la literatura latinoamericana, advierte que los criterios de organización del material en cuestión no responden, en sus trabajos, a las formaciones textuales o a los tipos discursivos a los que pertenecen los textos en cuestión. Por el contrario, el criterio organizativo está dado por el referente que todos comparten: el descubrimiento y la conquista de Indias (Mignolo, "Cartas, crónicas" 58). En el caso que estoy tratando, se puede decir algo similar: el criterio de selección de los textos no estará basado ni en criterios belleletrísticos (que implican una noción muy determinada y restringida de literatura), ni en la pertenencia a una familia discursiva (o textual, como prefiere Mignolo), ni en el tipo discursivo del que participan; siguiendo el criterio de Mignolo, organizaré el futuro corpus de acuerdo al referente que todos los textos escogidos comparten: el descubrimiento, ocupación o colonización de las tierras y habitantes de lo que a la postre se definiera como el Uruguay (actual). Mignolo hace la defensa de ese criterio:

por un lado, en el corpus textual cuyo referente es el descubrimiento y la conquista, el límite cronológico puede trazarse ... Esta cronología (que coincide con la época "colonial"), está marcada - a su vez - por una dimensión ideológica: lo que se denomina generalmente como "Indias" o "Nuevo Mundo", en los escritos anteriores al final del siglo XVIII y que, con más asiduidad, comienza a denominarse "América" en el siglo XIX, no sólo es ólo sabemosó un cambio de nombre, sino una modificación conceptual relacionada con un cambio político-económico que trazamos, cronológicamente, con la independencia. ("Cartas, crónicas" 58)

\footnotetext{
14 "dos de ellos nos son imprescindibles para la materia que tratamos: en primer lugar, los textos se clasifican por su pertenencia a la clase más inclusiva (literarios, filosóficos, religiosos, etc.). Denominaremos esta clase en su generalidad, formación textual; en segundo lugar, los textos se clasifican en el interior de una clase. Para el caso de la literatura contamos con la conocida clasificación en géneros y sus consiguientes subdivisiones. Denominaremos a esta segunda operación clasificatoria tipos discursivos haciendo al mismo tiempo la salvedad de que, por una parte, los tipos discursivos rescatan particularidades de la forma de los textos y, por otra, que podemos encontrar, en la historia de una cultura, tipos discursivos que no se relacionan estrechamente con una formación textual' (Mignolo, "Cartas, crónicas" 57-58).
} 
Si bien comparto los presupuestos teóricos expuestos por Mignolo, a los efectos de este trabajo particular, propongo ampliar la gama de tipos discursivos que este crítico tiene en cuenta en el trabajo citado (carta de relación, relación, crónica o historia y por último aquellos textos que exhiben caracteres estéticos mezclados con los historiográficos, $v$. gr.: La Araucana). ${ }^{15}$ Sigo más bien el criterio postulado por el mismo crítico en trabajos posteriores, donde no sólo propone incorporar todo tipo de textos verbales y no verbales (v. gr.: mapas) al corpus, sino que va un paso más lejos y los analiza ("Misunderstanding"16). Lo que propongo entonces es incorporar, por ejemplo, documentos tales como las actas y capitulaciones (de cabildos o audiencias), cédulas reales y asientos entre monarcas y descubridores (familias paleográficas no incluidas por Rojas). El criterio que anima esta inclusión es el mismo que anima los trabajos de Mignolo: la relevancia de esos textos concretos en relación a la cultura estudiada. Por ello, en futuras investigaciones, debería atenderse también a los mapas y otros documentos no-verbales:

tanto la complejidad idiomática de las colonias como la confrontación de culturas basadas en la oralidad y sociedades basadas en la escritura, hacen del período colonial un modelo ideal tanto para la reflexión sobre culturas y lenguas en contacto como del espectro de interacciones discursivas. ... la relevancia de la circulación de discursos en el Nuevo Mundo y entre el Nuevo Mundo y Europa para la comprensión del período, va más allá de lo escrito (puesto que importan las tradiciones orales y las escrituras no alfabéticas) y de lo escrito en castellano por hispanos. (Mignolo, "La letra" 138) ${ }^{17}$

Volviendo a los textos verbales, por su relevancia hay que incluir también a aquéllos escritos en lenguas diferentes al castellano (como ya lo había hecho Maggi) porque, en opinión de Mignolo:

Una cultura puede considerar significativos no sólo los textos escritos en la lengua de una cultura, sino también aquéllos que, escritos en otra lengua significan, de una manera o de otra (determinable en cada caso), en la cultura en cuestión. Un caso que se nos aparece de inmediato son las cartas de A. Vespucio y de Pedro Mártir de Anglería. Estos textos forman parte de la cultura hispana no por la lengua en que están escritos sino por

\footnotetext{
${ }^{15}$ Rojas también tomaba en consideración otros tipos discursivos pertenecientes a lo que él llamaba literatura administrativa o familias paleográficas, que serían: 1 . Actas y protocolos 2 . Informaciones y probanzas 3. Cartas y memoriales 4 . Descripciones y relaciones. Las actas y protocolos son el plus más interesante que ofrece la clasificación de Rojas, ya que las cartas y memoriales se confunden con las cartas relatorias de Mignolo, y las descripciones y relaciones con las relaciones a secas, provistas por este último crítico; de igual ambiguo carácter parecen ser las informaciones y probanzas, que por un lado se superponen con las relaciones y por otro con las acciones judiciales (Los coloniales I 176-192).

${ }^{16}$ También puede verse, por el mismo autor, "La grafia, la voz."

${ }^{17}$ Esta necesidad de analizar cuanto texto relevante se nos interponga en la investigación, ya había sido señalada por Ricardo Rojas: "El estudio completo de una literatura ha de abarcar, así, todo el logos del hombre, desde el folklore hasta el parnaso, desde el arte del rústico hasta el del culto. Por eso he sumado en mi obra, a la bibliografia poética, la poesía anónima; y a la prosa literaria, la literatura científica, desde Azara hasta Ameghino" (Los coloniales 75).
} 
referirse a un hecho crucial en la historia de esa cultura (por ejemplo, el descubrimiento); y por estar los escritos relacionados, de algún modo, con la estructura de poder de esa cultura en el momento de escribir. ("Cartas, crónicas" 58)

La inclusión de este tipo de textos es infrecuente (aunque no insólita) en la mayoría de los estudios literarios latinoamericanos, ya que los criterios de la historiografia literaria latinoamericana dominante no difieren mucho de los de la uruguaya. Baste recordar el criterio propuesto por Anderson Imbert:

La literatura que vamos a estudiar es la que, en América, se escribió en español. No ignoramos la importancia de las masas de indios. Pero, en una historia de los usos expresivos de la lengua española en América, corresponde escuchar solamente a quienes se expresaron en español. Por la misma razón no nos referiremos a los escritores que nacieron en Hispanoamérica pero escribieron en latín (como Rafael Landívar), en francés (como Jules Supervielle) o en inglés (como W. H. Hudson). (9)

Sin embargo, el contexto disciplinario que se vive hoy admite prácticas como las de Mignolo y otros estudiosos de los discursos coloniales, que haciendo caso omiso de criterios como el de Anderson Imbert, están produciendo cambios tales en el quehacer disciplinario que ya puede hablarse de una crisis de paradigma. ${ }^{18}$ A través de la brecha abierta por estos críticos, los textos coloniales sobre el Uruguay pueden entrar sin problemas al corpus latinoamericano.

Explicitados los criterios para la formación del canon tanto uruguayo como latinoamericano, parece conveniente preguntarse de dónde vienen, de dónde salen. En otras palabras, cómo se produce un canon, cómo se canoniza a los textos $\mathrm{y}$, sobre todo, quién lleva a cabo este tipo de empresa. Pero primero debe establecerse una clara diferencia entre lo que es el corpus textual de una cultura determinada, el cual, según Lambropoulous, consiste en la totalidad de los textos que la componen, y el canon de la misma (16). ${ }^{19}$ Cabe precisar, sin embargo, que el corpus no es realmente la totalidad de textos producidos por ( $y$ constituyentes de) una cultura (aunque es deseable la coincidencia corpus=totalidad de textos); la configuración del mismo refleja, más bien, los principios que regulan un quehacer disciplinario: es una construcción disciplinaria de un campo de investigación (Mignolo, "Tradiciones orales" 6-7). Es decir que, si lo que se quiere es dar debida cuenta de una

\footnotetext{
${ }^{18}$ Mignolo habla de "cambio de paradigma" ("La letra"). Prefiero hablar de crisis porque las nuevas prácticas todavía están compitiendo con las viejas. Otro aspecto a destacar es que esa crisis de paradigma no sólo se da en el campo de los estudios coloniales. También en los estudios sobre el siglo XX se están produciendo cambios: por ejemplo, la literatura testimonial está generando problemas teóricos y disciplinarios similares, porque su estudio presupone una redefinición de la historia literaria como práctica (Achugar, "Notas" 288); Mignolo, en el artículo citado, explica en qué consiste la redefinición del concepto de literatura (142).

${ }^{19}$ Una concepción similar tiene Alistair Fowler, quien equipara el corpus a la totalidad de lo escrito y lo llama "potential canon", para distinguirlo del "accesible", que es el que se consigue en las librerías (sujeto a contingencias materiales) y del "selectivo" (que escoge de entre lo que le ofrece el canon "accesible") y que es a su vez consecuencia del "crítico" que, naturalmente, es elaborado por los críticos (98-99).
} 
producción discursiva determinada, es conveniente incorporar al campo de estudio, si no todos, al menos la mayor cantidad de textos pertenecientes a la misma. El canon, a diferencia del corpus, no sólo no abarca la totalidad de los textos producidos por o sobre el sistema cultural del que es parte, sino que intencionalmente excluye determinados textos, privilegiando tan sólo una porción de los existentes, que representan "la estética y el gusto de quienes regulan las prácticas discursivas" (Mignolo, "Tradiciones orales" 7). Esto quiere decir que el canon de una literatura cualesquiera decide qué textos son relevantes (y cuáles no) para esa cultura. Es, entonces, el conjunto de lecturas obligadas de una literatura determinada. $\mathrm{O}$ incluso se puede, con un criterio pragmático, considerar al canon como equivalente a esa literatura determinada (dado que las lecturas obligatorias van oscureciendo a las que ni siquiera se consideran dignas de ser leídas ${ }^{20}$ ). O más aún, puede equipararse a una tradición cultural ( $l a$ Tradición de una cultura o una nación de que tanto hablan, generalmente, los hombres de Estado). ${ }^{21}$ De modo que un canon ejerce una labor modelizadora de conciencias, mediante la selección y digitación de los textos a ser leídos o estudiados. La pregunta que debemos plantearnos, me parece, es cómo se forma un canon, quiénes son responsables de su existencia y de su creación.

La literatrura, en tanto que formación discursiva, en tanto que institución, no es una entidad estable per se..$^{22}$ Este cambio de la categoría en cuestión está sujeto a las

${ }^{20}$ Lo que ocurre es que ese grupo selecto de textos (canon), es manipulado por los historiadores literarios (y demás profesores y académicos), quienes lo presentan como aquella serie exhaustiva de obras que realmente importan (the material that "matters", según Johnstone); excluyendo de este modo infinidad de materiales que no encajan en los patrones de selección, al mismo tiempo que se produce la ilusión de que no existe producción fuera de la propuesta (la "serie exhaustiva" mencionada más arriba) (Johnstone 29).

${ }^{21}$ Para Raymond Williams la tradición (que siempre es selectiva) es la expresión más evidente de lo dominante y hegemónico; una versión del pasado que contribuye a dar forma al presente (115); si bien el subrayado la es mío, está implícito en la caracterización misma que ofrece Williams. Para un análisis de la tradición hermenéutica que pretende ver la tradición occidental y burguesa como la única posible, negando la existencia de otras tradiciones que coexisten y compiten (aunque normalmente pierdan) con ella, véase el libro de John Brenkman (viii, 37-38). Para una crítica más específicamente literaria de la noción de "tradición" (entendida como única, homogénea, sin rupturas), como opuesta a "evolución literaria" (concepto que admite los quiebres y heterogeneidades), ver Jauss 17-18. Tan sólo para conocer una voz retardataria sobre este tema, el lector podría consultar a Wendell V. Harris, quien admite que un canon es la organización de una cultura provista por un grupo de interés, así como también la competencia de múltiples tradiciones por imponer su versión; el detalle que convierte a su enfoque en peculiar es que, en última instancia, no admite que una de esas tradiciones sea la dominante. En el terreno de la literatura latinoamericana, esa neutralización de lo heterogéneo (especialmente las manifestaciones culturales de origen rural) tuvo su culminación, precisamente, con la institucionalización de las literaturas nacionales, guardianas de aquello que se presentaba como la tradición, elaborada por y desde el enclave "civilizacional" por excelencia: la ciudad letrada (Rama, La ciudad letrada 90-91).

${ }^{22}$ Luego de un detallado análisis de las historias y antologías de la literatura de su país, la norteamericana Jane Tompkins constata las diversas variantes en los conjuntos de textos y autores ofrecidos por las distintas compilaciones; lo cual la conduce a la conclusión que enunciábamos más arriba: la literatura no es una entidad estable, sino una categoría cuyo contenido es variable (190). Respecto a la inestabilidad de la literatura, puede consultarse a Raymond Williams (53-54) y a Mignolo ("What is Wrong" 309). 
contingencias sociales y políticas de una comunidad dada (Tompkins 192). Lo que revela que los criterios para evaluar qué textos deben incluirse en el canon son, en esencia, contingentes. ${ }^{23}$ Habría entonces una relación de dependencia entre los juicios y valores literarios y las circunstancias históricas y sociales de la comunidad que los produce; pero esta relación no es unidireccional, ya que los criterios de valor también contribuyen a forjar cambios en las condiciones históricas (Tompkins 195). Esto último es fácil de ver, ya que estableciendo un conjunto de textos que se consideran de lectura necesaria y obligatoria, la élite que los establece tiene la posibilidad de influir en el imaginario social de su comunidad.

Señalado el carácter socialmente construído de los criterios para la formación de un canon literario, que revelan a las claras los valores que una cultura considera importantes (Graff y Cain 310), podemos volver a la pregunta anterior, relativa a quién o quiénes determinan el canon (ya que es obvio que éste se construye desde una perspectiva particular y no por generación espontánea). Una respuesta posible es, según Houston Baker, que "the canon is determined to some extent by class interests ... the past is always an ideologically conditioned version of events gone by" (citado en Kimball 38). Si se toma cuidadosamente esta afirmación, es decir, que los intereses de clase determinan en alguna medida la formación del canon, se puede comenzar a contestar la pregunta del párrafo anterior. El subrayado se debe fundamentalmente a que no parece plausible asignar la responsabilidad total y única a los intereses de una sola clase en lo que respecta a la construcción de una tradición literaria. Debe haber algún compromiso entre clases, ya que para imponer su hegemonía, la clase dominante debe ceder algún espacio de participación, por mínimo que sea, a sus adversarios. ${ }^{24}$ Pero los sujetos (pertenecientes a las diversas clases sociales) no siempre actúan mecánicamente en función de los intereses de su clase; existen y actúan también en su condición de miembros de los que Losada llama (algo vagamente) grupos sociales (215-252), ${ }^{25}$ categoría que tiene la virtud de zafar del corset de la mera pertenencia a una clase. ${ }^{26}$ En este sentido los académicos, los profesores de

23 "We are always making choices, and hence value judgments, about which books to read, teach, write about, recommend, or have on our shelves. The point is not that these discriminations are baseless; the point is that the grounds on which we make them are not absolute and unchanging but contingent and variable" (Tompkins 193).

${ }^{24}$ Me adhiero aquí, como es obvio, a la posición teórica que interpreta la noción gramsciana de hegemonía menos como dominio impuesto por una clase a otras que como una lucha de posiciones, en la que la clase hegemónica debe hacer concesiones a los intereses de otras clases (y defenderlos como suyos) para cimentar su liderazgo político y espiritual. Para una excelente exposición de esta interpretación de la noción, ver: Chantal Mouffe "Hegemony and Ideology in Gramsci" Ed. Chantal Mouffe, Gramsci and Marxist Theory (London: Routledge and Kegan Paul, 1979) 168-204.

${ }^{25}$ Puntos de contacto con la noción "grupos sociales" pueden encontrarse en la noción "formaciones", propuesta por Raymond Williams (117-120).

${ }^{26}$ Aunque la potencial utilidad de tal categoría queda parcialmente anulada en la utilización que de ella hace Losada. Una de las objeciones posibles al desarrollo de su modelo podría centrarse en uno de sus postulados centrales: la(s) literatura(s) es producto de la praxis (exclusiva) de determinado(a) grupo(s) social(es); con lo cual se deja afuera toda la gama de interdependencias y mutuas (dialécticas) influencias que se ejercen entre los distintos grupos que actúan en un marco societario. 
enseñanza secundaria, los escritores, los periodistas, actúan con relativa autonomía y con criterio corporativo, en tanto que miembros de un grupo. No debemos, entonces, darnos por satisfechos con la antedicha constatación; hay también que ver qué instituciones contribuyen a la realización de esa empresa.

Lambropoulos afirma que es la crítica, en tanto que institución, la responsable de la formación de una literatura determinada (4). ${ }^{27}$ También sostiene que son los críticos, teóricos, profesores, los que construyen una literatura:

literature does not inhere in texts but is produced by the application and interaction of established reading techniques. To analyze it we must look into those cultural practices that make it possible and meaningful. We need to see how the game of "reading literature" is played, how the relevant rules are authorized, who can participate in it, where it can take place, and also what is at stake. (subrayados míos, 14)

Es a estas estrategias o técnicas de lectura que se debe prestar particular atención. Y como se desprende de todo lo antedicho, las tales estrategias no son estables y no emergen en soledad, sino que surgen en contextos históricos determinados (Tompkins 187). Creo haber descrito, para el caso uruguayo, cuáles son las estrategias de lectura propuestas por la crítica para la formación del canon. ${ }^{28}$ Sin embargo, lo que intento cuestionar desde estas páginas no es el canon concreto con que cuenta la literatura uruguaya. Tampoco creo que sea suficiente conformarse con la mera agregación de determinados textos al conjunto ya existente. La idea es otra.

Como se habrá apreciado, en la precedente revisión de las historias y antologías de la literatura uruguaya me centré tan sólo en los criterios de selección, en las estrategias de lectura que la constituyen en tanto que institución, sin hacer mayor alusión a los productos concretos que la conforman. Esta actitud surge de la creencia de que el canon no es un mero conjunto de textos privilegiados, una mera selección que se agota en sí misma, sino más bien el producto de un sistema. A este sistema lo llamaré, a falta de mejor vocablo, traduciendo a Ross Chambers, sistema de canonicidad. ${ }^{29}$ En otras palabras, el o los criterios

\footnotetext{
${ }^{27}$ Opinión compartida por Terry Eagleton: "Literary theorists, critics and teachers, then, are not so much purveyors of doctrine as custodians of a discourse. Their task is to preserve this discourse, extend and elaborate it as necessary, defend it from others forms of discourse, initiate newcomers into it and determine whether of not they have succesfully mastered it" (201).

${ }^{28}$ Criterios que rigen también para su difusión por parte de las instituciones pedagógicas (tanto de nivel secundario como terciario) y de sus integrantes (profesores, académicos). Basta echar un vistazo a los programas de literatura (especialmente de secundaria, ya que en la universidad se están produciendo algunos cambios) para percibir la casi total ausencia de textos que no cumplen con los requisitos para ser considerados obras maestras, bellas letras o, más simplemente, literatura: allí no aparecen los nombres de Jaime Roos, Clemente Padín, Julia Möller, Antolín, el gauchito del talud (Carlos Modernell) y tantos otros productores de discursos simbólicos.

29 "When we accede to the idea that certain texts are in the canon while others are not, we are in fact acceding to the system of canonicity, of which the canon is a product. It is clear, for instance, that the supposedly canonical texts are so only by virtue of there being texts excluded from that category; thus the noncanonical works are an indispensable part of the whole system, of which the canon is another part. It would theoretically take only one exclusion to make a canon; one exclusion
} 
que determinan la inclusión o la exclusión de textos. Mi propósito es proponer para la literatura uruguaya un nuevo criterio de formación del canon, que se parezca más a un corpus completo que a una selección..$^{30}$ No parece necesario, sin embargo, proponer cambios para los criterios de formación del corpus latinoamericano colonial. Como ya se ha señalado, estos cambios están en marcha y como consecuencia el corpus está expandiéndose. La propuesta en el caso uruguayo es un intento de neutralizar el modus operandi de una comunidad imaginada (o interpretativa) que escoge y produce los textos que mejor se adaptan al proyecto de creación de una nacionalidad, que casualmente tiene a dicha comunidad como protagonista o líder de la narrativa que fundamenta el sistema hegemónico. ${ }^{31}$ En estas circunstancias, la crítica va a producir un canon que sea tributario de las ideas que la comunidad hegemónica tenga sobre la nacionalidad..$^{32}$

De modo que la operación de revisión de los criterios de canonicidad en una literatura no tiene otro fin que dar la oportunidad, a aquellas comunidades excluídas, de estar igualmente representadas en el canon, ya sea in prosentia, mediante la inclusión de los textos producidos por ella (en el caso de Uruguay no he encontrado ninguno de esta índole), o in absentia, mediante la deconstrucción de los textos pertenecientes a las comunidades hegemónicas.

Para dar una mejor idea de las peculiaridades del corpus uruguayo, pero también de las similitudes con el corpus latinoamericano de este período, creo que una buena estrategia es hacer dialogar a ambos. De este modo quedará registrada, no sólo su pertenencia a un área geopolítica con la que comparte rasgos comunes (situaciones históricas y políticas

would be a necessary and sufficient condition. Furthermore, since canonicity is systemic, every excluded text is potentially includable in the canon, and every included text is a possible candidate for exclusion ... What finally matters in the system of canonicity, then, is not so much which texts are included and which are excluded but what the criteria are that will count at a given time for inclusion or exclusion" (Chambers 18).

${ }^{30}$ Es pertinente aquí la aclaración que hace Mignolo, de que no se trata de sustituir el canon por el corpus, sino de incorporar el canon al corpus ("Tradiciones orales" 8). En el caso de la producción discursiva correspondiente al período colonial en el Uruguay, no existe previamente un "canon colonial" al que incorporar (sin privilegiarlo) al corpus. Lo que sí existe es un canon literario general del que todo (o casi todo) el corpus colonial está excluído.

${ }^{31}$ La noción "comunidad imaginada" ha sido elaborada por Benedict Anderson (ver especialmente las páginas 13-16). Se trata de un grupo social que se percibe a sí mismo como entidad (como nación), y que se construye en contraposición a otras comunidades. Las comunidades interpretativas son definidas por Fish como aquéllas que comparten una forma de ver el mundo, una serie de estrategias de decodificación de la realidad que la diferencian de otras comunidades (13-14).

${ }^{32}$ Algo de esto puede verse en el libro de Lambropoulos (14). Este es el modus operandi de la historia literaria como disciplina, la cual, según Jauss, ve al sistema literario como una serie de obras literarias que representan (o buscan) la nacionalidad; el historiador literario construye esa serie a partir de una idea guia: la individualidad nacional $(6,8)$. Es desde esta perspectiva que suscribo las siguientes afirmaciones de Lambropoulos: "I conduct my analysis of the strategies employed in the context of the politics of interpretive communities and intend to show how invested interests are served by text productions. Such communities, I imply, have achieved authority when they can participate succesfully on the formation of a canon engraved and stored in the national unconscious" (16). 
similares), sino también su peculiaridad, que la distingue como una de las literaturas "nacionales" a tener en cuenta en el proceso general de la literatura latinoamericana. Esta última afirmación merece una aclaración: el hablar de una literatura "nacional" no es lo mismo que incurrir en lo que Pizarro y Pacheco llaman (invocando a Gutiérrez Girardot) una "lectura provinciana":

La lectura nacionalista constituye otra línea de orientación en las periodizaciones latinoamericanas. Ella valora la noción de "unificación nacional" y no organiza el desarrollo de la historia literaria sino en términos autónomos, en desmedro de una dirección continental o universal. Se convertiría así, como señala Rafael Gutiérrez Girardot, en una lectura "provinciana", que periodiza los fenómenos sin relación con otros similares de otras literaturas. En este sentido muchas veces aquello que se advierte como peculiaridad de nuestra literatura, es sólo una peculiaridad relativa, en la medida en que ella existe también en otras literaturas. (71)

Es este delicado diálogo entre lo latinoamericano y lo uruguayo propiamente dicho lo que me interesa. Una lectura provinciana, además de exponer al investigador a los riesgos referidos por Pizarro y Pacheco, se justifica aún menos en el presente caso; debido a que la historia común de los pueblos que componían la gobernación del Plata y luego el Virreynato del Río de la Plata, generó un corpus de textos que tienen, simultáneamente, como referente a varios de los futuros estados/nación (Uruguay, Argentina, Paraguay) de la región. Y el sentimiento de pertenencia a una comunidad (o la descripción de esa comunidad) abarcaba indistintamente, en esos autores, a los territorios de esos estados/nación modernos. ${ }^{33} \mathrm{Sin}$ llegar a exageraciones desmedidas que lleven a confundir las naciones de la región con el Mercosur (mercado común del Cono Sur, ya en marcha), es innegable la fuerte interconexión entre las historias "nacionales" de aquéllas y los textos que propongo incorporar a los estudios coloniales latinoamericanos. Debido a esta cercanía, me parece conveniente practicar lo que se ha dado en llamar comparatismo contrastivo. ${ }^{34}$ Como consecuencia de ello, sería conveniente apelar a la comparación de las estrategias discursivas de los textos de la región con aquéllas operantes en discursos coloniales paradigmáticos (el Diario de Colón, La Araucana de Ercilla, las Cartas de Cortés, etcétera). Varios de los mecanismos retóricos que informan a estos últimos estarán presentes (con variantes, claro está) en los textos sobre el Uruguay. Por supuesto, los dispositivos retóricos no son los únicos elementos que los textos coloniales sobre el Uruguay comparten con sus similares del resto de América.

${ }^{33}$ Este hecho ya era percibido por Ricardo Rojas, quien, enfrentado a la tarea de fijar los límites de la literatura argentina, afirmaba: "No olvidemos, en fin, que americanos como el paraguayo Ruy Díaz de Guzmán, el uruguayo Florencio Sánchez y el nicaragüense Rubén Darío no pueden ser explicados si se los separa del medio argentino donde florecieron. Es, pues, el espírito (sic) mismo de la nacionalidad, y no los elementos materiales que la constituyen - territorio, política o ciudadania-, lo que debe servirnos de criterio cuando clasifiquemos la materia literaria y queramos fijar la extensión de esta asignatura. Por eso la geografía de mi obra abarca todo el virreinato del Plata, y su cronología toda la colonización, sin lo cual no podría explicarse nuestra Argentina actual" (Los gauchescos I 37).

${ }^{34}$ Para una descripción del mismo ver las ideas de Ana Pizarro (44). 
También están todos los factores de índole política, económica y cultural que son consecuencia del encuentro colonial. A pesar de que esto es evidente, los practicantes de los estudios coloniales no se han ocupado, todavía, de los textos de la región del Plata. Pero como a nadie se le va a ocurrir negar la pertenencia de estos textos al corpus latinoamericano, dejemos este asunto y pasemos a los rasgos que los caracterizan. Estos, quizá, contribuyan a explicar parcialmente el por qué de ese olvido.

Para comenzar con una de las peculiaridades de los discursos coloniales uruguayos, se puede decir que no se halla en todo su corpus ningún texto emanado por las etnias originarias de su territorio. Ésta es una diferencia importante con otras literaturas de América Latina, que sí presentan casos de este tipo, lo cual tiene sus consecuencias, como se verá. Por ejemplo, en lo referente a una de las características de buena parte de la producción discursiva latinoamericana: la heterogeneidad. Cornejo Polar la define del modo siguiente: "Histórica y estructuralmente la heterogeneidad socio-cultural que es la base del indigenismo se encuentra prefigurada en las crónicas del Nuevo Mundo. Aquí se percibe por vez primera ese complejo proceso a través del cual un universo se dispone a dar razón de otro distinto y ajeno: el deslumbrado español que intenta descifrar el sentido de la nueva realidad con que se enfrenta" (33).

Y se puede agregar que no sólo el español es el deslumbrado: todos los europeos occidentales se enfrentaban al mismo portento. Pues bien, la heterogeneidad latinoamericana es la misma que se percibe en la tradición discursiva uruguaya, pero con una peculiaridad: lo heterogéneo tiene lugar sólo en textos escritos desde la perspectiva europea o criolla; nunca en textos de indígenas (que no existen). La consecuencia de esto es que en el Uruguay lo que hay es un universo discursivo unidireccional, de una sola senda; una producción textual que exhibe siempre su índole conflictiva, pero desde una perspectiva única. ${ }^{35} \mathrm{Si}$ bien esta unidireccionalidad de perspectiva es común al período colonial latinoamericano en general (debido a la hegemonía de la cultura europea), en el área del Río de la Plata presenta un carácter más marcado, debido a la ausencia de textos aborígenes. Lo cual provocará la necesidad de un trabajo adicional de parte del analista, si lo que se quiere es realmente establecer un panorama más o menos adecuado de la economía discursiva del período.

Otra diferencia significativa entre los discursos producidos sobre el Uruguay en el período colonial, y buena parte del resto de la producción latinoamericana de la misma época, reside en la forma en que se realizó la conquista u ocupación allí. Otras tierras, tales como las de los actuales Perú o México, fueron las que sufrieron el pillaje de las primeras visitas europeas. Cronológicamente, las islas del Caribe los padecieron incluso antes que los grandes imperios Inca y Azteca. Predispuestos los conquistadores (cuyo objetivo principal eran los metales preciosos y las especias) a encontrar tesoros y maravillas

\footnotetext{
${ }^{35}$ Perspectiva unidireccional que, según Cornejo Polar, implica un conflicto de intereses: "es obvio que no existe coincidencia -en la inmensa mayoría de las veces- entre los intereses que expresa el cronista y los que, en el orden de la realidad, tiene el referente [esto es, su objeto de discurso]" (36). Aquí debemos interpretar "referente" como término que incluye no sólo la geografía (que no parece poder ser considerada sujeto de interés), sino también al habitante originario, que sí tiene intereses opuestos a los expresados por el conquistador.
} 
en las Indias Occidentales, arrasaron con aquellas culturas. Pero para su sorpresa, la naturaleza no había dotado equitativamente de ese tipo de riquezas a todas las tierras descubiertas. Las que hoy constituyen el territorio de la República Oriental del Uruguay se encontraban entre aquéllas que no poseían tales tesoros. Más de un historiador uruguayo destaca a este hecho como una de las causas de la tardía colonización de su territorio. Eran tierras "de ningún provecho." ${ }^{36} \mathrm{La}$ fertilidad de sus suelos, las posibilidades de desarrollo de vida comunitaria, y de fundar pueblos prósperos, no fueron percibidas sino mucho más tarde. Es que en los primeros años que sucedieron al descubrimiento, los europeos no estaban tan interesados en este tipo de tierras, sino en las que producían oro y plata. Lo cual explica por qué los primeros expedicionarios que tocaron tierra uruguaya intentaban, en realidad, buscar una vía de acceso a las minas de la zona andina. Por otro lado, la ausencia de grandes y sofisticadas civilizaciones en esa región del continente puede haber sugerido al conquistador que las posibilidades de establecer una sociedad "civilizada" en la misma no eran muchas.

Se debe tener en cuenta que, además del escaso esfuerzo que los españoles realizaran por poblar la ribera oriental del Río Uruguay, las pocas veces que lo intentaron, fueron repelidos por los pobladores originarios. El natural guerrero de charrúas y minuanes, por citar tan sólo los más rebeldes, fue un firme obstáculo a las pretensiones del conquistador. Cada pueblo que fundaban los expedicionarios era sistemáticamente atacado y, en algunas ocasiones, destruido por los nativos de aquellas tierras. Esto se ve claramente en los textos sobre las expediciones de Solís y Gaboto, las "Historias" (de Ruy Díaz de Guzmán y Barco Centenera, entre otros), y tantos otros. ${ }^{37}$

Todos estos factores trajeron aparejada una ocupación europea tardía del territorio (en 1680 los portugueses, en 1724 los españoles), si se la compara con el resto de América. Las consecuencias de ésto son, como puede imaginarse, de vastísimo alcance. La primera de ellas es que la cultura europea que los españoles llevaron a Uruguay fue diferente a la que impusieron a los territorios previamente colonizados. Ya no estamos en el renacimiento sino en los albores del siglo XVIII. De ahí que la formación de centros poblados (y las sociedades que se desarrollaron en ellos) haya producido estructuras culturales bastante idiosincráticas. Otra consencuencia de la colonización tardía es el tipo humano que colonizó el territorio: no hubo capitanes que se asentaran con sus tropas a sangre y fuego. Por el contrario, los primeros pobladores de Montevideo fueron familias de labradores, no soldados; el fundador de esta ciudad fue un funcionario de la corona (si bien es cierto que con un pasado guerrero) y no un conquistador persiguiendo El Dorado (en la segunda década del siglo XVIII ya se habían disipado muchos de - aunque no todos- los malentendidos sobre el Nuevo Mundo). Un criterio colonizador, basado en el asentamiento y población con el fin de explotar los suelos y ganados locales, sustituyó al que presidiera la conquista de otros territorios americanos, y a los intentos de conquista del territorio oriental. De más está decir que no es lo mismo un Zabala (fundador de Montevideo) que

\footnotetext{
${ }^{36}$ Ver las obras de Zum Felde (Proceso intelectual 31-33; Proceso histórico 12-13) y, especialmente, de Ares Pons (9-10), donde este último hace referencia a la denominación "tierras de ningún provecho" aplicada a las tierras del Uruguay.

${ }^{37}$ Para el estudio de estos y otros textos, remito a mi tesis doctoral (Verdesio 1992).
} 
un Pizarro, un Hernandarias (introductor de la ganadería en territorio uruguayo) que un Valdivia. ${ }^{38}$

Otro efecto de esta situación es que el proceso de transculturación, característico del resto del subcontinente, en la Banda Oriental no sólo es posterior (ya que el asentamiento de poblaciones europeas lo es), sino que es de índole esencialmente diferente al del resto de Latinoamérica. ${ }^{39} \mathrm{Si}$ bien existía un cierto contacto entre los charrúas y la cultura dominadora (entraban a las ciudades y a las pulperías, refieren los textos de Azara y Pernetty ${ }^{40}$ ), este tipo de participación en las estructuras de la cultura occidental no dejaba de tener un mero carácter ocasional, sin implicar integración o aceptación significativas. ${ }^{41}$

Como consecuencia de esta precaria relación entre los nativos y el europeo, y de la escasa transculturación consecuente, pocos vestigios han quedado de las culturas aborígenes. La falta de conocimiento mutuo que se dio entre las culturas en conflicto motiva la situación de orfandad en que nos encontramos en el siglo XX para reconstruir o imaginar más o menos adecuadamente lo que eran las culturas nativas. ${ }^{42}$ Debido a la falta de documentación sobre las culturas originarias, nos encontramos con grandes dificultades para devolver a la economía discursiva del período colonial algo de su perdida complejidad, ya que ha quedado sin representación textual un sector importante del conjunto de comunidades imaginadas que la componían. Uno de los caminos para esta reconstrucción es el de los antropólogos (cuyas recientes excavaciones están redescubriendo las etnias desaparecidas); otro es el que propongo tomar aquí: emprender la deconstrucción de los textos del conquistador; desarmar su andamiaje retórico y conceptual; leer, entre líneas, en sus silencios; interpretar sus omisiones.

\footnotetext{
${ }^{38}$ Para sintetizar lo dicho antes, viene a cuento este pasaje de Raúl Montero Bustamante, aparecido en su "Prólogo" a El gobierno colonial: "Si los fundadores de las ciudades del siglo XVI fueron hombres vestidos de hierro, los que fundaron, poblaron y organizaron Montevideo fueron funcionarios de peluca rizada y casaca de seda, labriegos y menestrales, cristianos viejos de sangre limpia y solar conocido, que no tuvieron otra aspiración que la de labrar la tierra, sujetar a rodeo el ganado salvaje que poblaba los campos y servir a Dios y al Rey, sea con la vara de la justicia de los regidores, sea con el mosquete en los días de peligro para la ciudad" (sin página).

${ }^{39}$ El concepto pertenece al antropólogo cubano Fernando Ortiz, quien lo define así: "Entendemos que el vocablo transculturación expresa mejor [que el de aculturación] las diferentes fases del proceso transitivo de una cultura a otra, porque éste no consiste solamente en adquirir una cultura, que es lo que en rigor indica la voz angloamericana aculturación, sino que el proceso implica también necesariamente la pérdida o desarraigo de una cultura precedente, lo que pudiera decirse una parcial desculturación, y, además, significa la consiguiente creación de nuevos fenómenos culturales que pudieran denominarse neoculturación." (citado en Rama, Transculturación 32- 33). Por ésta y por otras razones que vamos a ver, la utilización de la categoría antropológica acunada por Ortiz sólo puede hacerse, en el caso de las tierras del Uruguay, en un sentido débil.

${ }^{40}$ Para un análisis de estos textos, ver mi tesis doctoral (Verdesio, "Hacia una historia").

${ }^{41}$ Por todas estas razones, el término transculturación debe entenderse, para el caso uruguayo, en un sentido "débil."

${ }^{42}$ En este sentido, otras naciones latinoamericanas son más afortunadas, dado que conservan numerosos textos escritos y testimonios orales que habilitan al investigador a tener mayores esperanzas en su tarea de restitución o reconstrucción.
} 
Otra diferencia relevante entre la producción textual colonial latinoamericana y la uruguaya es que, debido a la tardía colonización, la existencia de textos pertenecientes a la familia discursiva literatura es mucho más exigua en la última nombrada. Lo que no debe ser interpretado como algo negativo, sino más bien como la constatación de un hecho. No hay Sor Juanas en el Uruguay colonial, pero pueden encontrarse equivalentes a los Colones y Corteses del continente en sus Garcías y Hernandarias. Todos ellos, sin excepción y sin perjuicio de las diversas formaciones y tipos discursivos a los que pertenecen, son de gran relevancia para las respectivas culturas de las que son parte (y contribuyeron a forjar). Sin embargo, debe consignarse como un rasgo distintivo del desarrollo de la cultura que nos ocupa, la ausencia de este tipo de producción comúnmente identificada con las nociones de alta cultura y bellas letras. ${ }^{43}$ Es quizá por esta causa que los textos sobre el Uruguay no han sido estudiados hasta el momento. Hipótesis verosímil, ya que los criterios para la formación del canon latinoamericano colonial estaban inspirados, hasta hace pocos años (hasta la aparición de criterios como el de Mignolo), en una concepción belleletrística similar a la de Anderson Imbert. Hoy, en el marco de la crisis de paradigma que vive la disciplina, ya no existen buenas razones para ignorar la producción discursiva colonial de esa parte del continente.

En suma, la consideración de estas particularidades será factor de importancia para el estudio del proceso de construcción de comunidades y vida social en la región que nos ocupa. Estos rasgos distintivos serán los que nos permitan, en adelante, realizar un estudio específico (pero no totalmente independiente de lo latinoamericano) de los discursos producidos en y sobre lo que hoy es la comunidad imaginada identificada como Uruguay. Discursos que serán producto (al mismo tiempo que forjadores) de dicha macrocomunidad. ${ }^{44}$ De ahí la utilidad de su inclusión en el corpus de la literatura uruguaya. De

\footnotetext{
${ }^{43}$ Hay que recordar aquí lo que informa (desde su perspectiva, claro está) Carlos Roxlo. A pesar de su extensión, vale la pena transcribir entero el fragmento, que se justifica por el completo panorama que ofrece sobre lo que eran las posibilidades de educación en la cultura occidental por aquellos tiempos: "En Montevideo mismo, durante el coloniado (sic), el denuedo sobra y la cultura falta. Tanto es así que la primera de las escuelas que tuvo la capital fue fundada por los jesuitas recién en 1744, pasando esa escuela, cuando se llevó a cabo la expulsión de la célebre orden, a ser propiedad de los padres del Convento de San Francisco. A esta escuela siguió, en 1796, una escuela laica dirigida por don Mateo Cabral; pero tanto en estos dos establecimientos como en el colegio para niñas pobres establecido en 1795 por doña María Clara Zavala, lo único que se enseñaba era a rezar, un poco de gramática y algo de aritmética, siendo mucha la disciplina y cosa corriente los palmetazos. Aun esto mismo, con ser tan primordial y defectuoso, no alcanzó a los criollos de la clase media ni llegó jamás a los campesinos de las chacras próximas, monopolizando la juventud aristocrática, de viejo y puro abolengo español, lo mejor de la escasa siembra espiritual de la escuela laica y la escuela monjil. No teníamos ni universidades, ni bibliotecas públicas, ni librerías, que pudiesen ampliar o servir de auxilio a la acción de la escuela. El primer periódico nacido aquí, La Estrella del Sur, no duró dos meses" (30-31).

${ }^{44}$ Sobre la importancia de las primeras representaciones del territorio y habitantes uruguayos como punto de partida para la posterior formación de comunidades (imaginadas e interpretativas) y sus visiones de sí mismas, pueden verse mis artículos "La República" y "Escritura e identidad cultural." Sobre las representaciones coloniales como forjadoras de "América" (con énfasis en las estructuras del sistema discursivo europeo que las articula), puede verse el libro de José Rabasa.
} 
ahí su importancia en tanto que desafío al canon (y al sistema de canonicidad) propuesto por las historias de la literatura uruguaya. Pero también creo necesaria la incorporación de estos textos al corpus (y al canon) de los estudios coloniales latinoamericanos, especialmente si lo que se busca es la reconstrucción del universo discursivo colonial. Sin ellos el corpus latinoamericano colonial quedará incompleto. Y si se adhiere al criterio propuesto por Mignolo (referido más arriba), el asunto es todavía más claro: los textos coloniales son nuestro objeto de estudio disciplinario porque tienen como tema o (mejor aún) construyen la América colonial. Consecuentemente, si concebimos a esta última en tanto que referente de (o creado por) un discurso, nos están faltando algunas piezas del rompecabezas. Sólo con la incorporación de los textos sobre la región del Plata estaremos en condiciones de intentar una reconstrucción más acabada de ese complejo referente que es la América colonial. $^{45}$

\section{BiBliografía}

Achugar, Hugo. "Literatura/literaturas y la nueva producción literaria latino-americana". Revista de crítica literaria latinoamericana 29 (1989): 153-165.

"Notas sobre el discurso testimonial latinoamericano". La historia de la literatura iberoamericana. Memorias del XXVI Congreso del Instituto Internacional de Literatura Iberoamericana. Hanover, NH: Ediciones del Norte, The City College of The City University of New York, 1989. 280-293.

Anderson, Benedict. Imagined Communities. London: Verso, 1983.

Anderson Imbert, Enrique. Historia de la literatura hispanoamericana I. La colonia. Cien años de república. $2^{\mathrm{a}}$ edición. México: Fondo de Cultura Económica, 1987.

Bauzá, Francisco. Estudios literarios. Colección de clásicos uruguayos. Montevideo: Biblioteca Artigas, 1953.

Bollo, Sarah. Literatura Uruguaya. 1807-1965. Montevideo: Orfeo, 1965.

Brenkman, John. Culture and Domination. Ithaca and London: Cornell University Press, 1987.

Casal, Julio J. Exposición de la poesía uruguaya. Montevideo: Claridad, 1940.

Chambers, Ross. "Irony and the Canon". Profession 90. The Modern Language Association of America (1990): 18-24.

Cornejo Polar, Antonio. Literatura y sociedad en el Perú: La novela indigenista. Lima: Lasontay, 1980.

Eagleton, Terry. Literary Theory. An Introduction. Minneapolis: University of Minnesota Press, 1983.

Fish, Stanley. "Introduction or How I Stopped Worrying and Learned to Love Interpretation". Is There a Text in This Class? Cambridge and London: Harvard University Press, 1980. 1-17.

Fowler, Alistair. "Genre and the Literary Canon". New Literary History 11.1 (1979) 97119.

${ }^{45}$ Este proyecto de incorporación de los textos rioplatenses (especialmente los que versan sobre el Uruguay) a los estudios coloniales latinoamericanos ya fue propuesto por Gustavo Verdesio en "Hacia una historia". Por el mismo autor, puede consultarse un estudio centrado en uno de esos textos coloniales rioplatenses ("La Argentina”), sobre el poema épico/historia de Barco Centenera. 
Gallinal, Gustavo. "El primer Parnaso oriental". Historia sintética de la literatura uruguaya. Ed. Carlos Reyles. Montevideo: Alfredo Vila, 1931. 5-31.

Graff, Gerald y William E. Cain. "Peace Plan for the Canon Wars". The Nation (March 6, 1989) 310-312.

Harris, Wendell V. "Canonicity". PMLA 106.1 (1991) 110-121.

Jauss, Hans Robert. Toward an Aesthetic of Reception. Traducción Timothy Bahti. Minneapolis: University of Minnesota Press, 1982.

Johnstone, Robert. "The Impossible Genre: Reading Comprehensive Literary History". PMLA 107.1 (1992): 26-37.

Kimball, Roger. "The Academy Debates the Canon". The New Criterion (September 1987): 31-43.

Lambropoulos, Vassilis. Literature as National Institution. Studies in the Politics of Modern Greek Criticism. Princeton: Princeton University Press, 1988.

Losada, Alejandro. "Modelo de los sistemas literarios como instituciones sociales en América Latina". Creación y praxis. Lima: Universidad Mayor de San Marcos, 1976. 215-252.

Maggi, Carlos. Capítulo Oriental 4. La colonia y la patria vieja: actores y testigos. Montevideo: Centro Editor de América Latina, 1968.

Mignolo, Walter. "What is Wrong with the Theory of Literature?" The Sign. Semiotics around the World. Michigan Slavic Contributions 9. L. Matejka, R. W. Bailey, P. Steiner. editores. Ann Arbor: Michigan Slavic Publications, 1980. 305-327. "Cartas, crónicas y relaciones del descubrimiento y la conquista". Historia de la literatura hispanoamericana. Tomo I. Epoca colonial. Luis Iñigo Madrigal, editor. Madrid: Cátedra, 1982. 57-117.

"La letra, la lengua, el territorio (o la crisis de los estudios literarios coloniales)". Dispositio 28-29 (1986): 135-160.

"Tradiciones orales, alfabetización y literatura (o de las diferencias entre el corpus y el canon)". IX Congreso internacional da associação de lingüistica e filologia da América Latina. Campinas, Brasil, 1990. 1-11.

"La grafía, la voz y el silencio: las relaciones geográficas de Indias en el contexto de las letras virreinales". Insula 552 (1990): 11-12.

"Teorizar a través de fronteras culturales". Revista de crítica literaria latinoamericana 33 (1991): 103-112.

"Misunderstanding and Colonization: The Reconfiguration of Memory and Space". South Atlantic Quarterly 92.2 (1993): 209-260.

Montero Bustamante, Raúl. El Parnaso oriental. Antología de poetas uruguayos. Montevideo, 1905.

Prólogo. El gobierno colonial en el Uruguay y los orígenes de la nacionalidad. $T$

I. Colección de clásicos uruguayos. Por Pablo Blanco Acevedo. Montevideo: Biblioteca Artigas, 1975.

Mouffe, Chantal. "Hegemony and Ideology in Gramsci". Gramsci and Marxist Theory.

Ed. Chantal Mouffe. London: Routledge and Kegan Paul, 1979. 168-204.

Pizarro, Ana, Ed. La literatura latinoamericana como proceso. Buenos Aires: Centro Editor de América Latina, 1985. 
Pizarro, Ana y Carlos Pacheco. "Aprehender el movimiento de nuestro imaginario social". Pizarro 79-96.

Rabasa, José. Inventing America. Spanish Historiography and the Formation of Eurocentrism. Norman and London: University of Oklahoma Press, 1993.

Rama, Ángel. Transculturación narrativa en América Latina. México: Siglo XXI, 1982. La ciudad letrada. Hanover, NH: Ediciones del Norte, 1984.

Rojas. Obras. Tomo X. La literatura argentina. Los coloniales I. Buenos Aires: "La Facultad", 1924.

Obras. Tomo X. La literatura argentina. Los gauchescos I. Buenos Aires: "La Facultad", 1924.

Roxlo, Carlos. Historia crítica de la literatura uruguaya. El romanticismo. Tomo I. Montevideo: Barreiro y Ramos, 1912.

Tompkins, Jane. Sensational Designs: The Cultural Work of American fiction. New York: Oxford University Press, 1985.

Verdesio, Gustavo. "Hacia una historia de los discursos coloniales en el Uruguay". Diss. Northwestern University, 1992.

"La República Árabe Unida, el maestro soviético y la identidad nacional". Hugo Achugar y Gerardo Caetano Eds. Identidad uruguaya: ¿mito, crisis o afirmación?" Montevideo: Ediciones Trilce, 1992. 97-107.

"La Argentina: tipología textual y construcción de los referentes". Revista de crítica literaria latinoamericana 38 (1993): 345-360.

"Escritura e identidad cultural en el Uruguay colonial". Letterature d'America: Rivista Trimestrale XIII/49. Roma: Universita di Roma, 1993.

Williams, Raymond. Marxism and Literature. Oxford: Oxford University Press, 1977.

Zum Felde, Alberto. Proceso intelectual del Uruguay. T. I. Montevideo: Imprenta Nacional Colorada, 1930.

Proceso histórico del Uruguay (1920). Montevideo: Arca, 1967. 